\title{
COVID-19 vaccine effectiveness against hospitalization due to SARS-CoV-2: A test negative design study based on SARI sentinel surveillance in Spain
}

Clara Mazagatos Ateca ${ }^{1}$, Concepción Delgado-Sanz ${ }^{1}$, Susana Monge ${ }^{1}$, Francisco Pozo ${ }^{1}$, Jesús Oliva ${ }^{1}$, Virginia Sandonis ${ }^{1}$, Ana Gandarillas ${ }^{2}$, Carmen Quiñones-Rubio ${ }^{3}$, Cristina Ruiz-Sopeña $^{4}$, Virtudes Gallardo-García ${ }^{5}$, Luca Basile ${ }^{6}$, María Isabel Barranco-Boada ${ }^{7}$, Olga Hidalgo-Pardo ${ }^{8}$, Olalla Vazquez-Cancela ${ }^{9}$, Miriam García-Vázquez ${ }^{10}$, Amelia Fernández-Sierra ${ }^{11}$, Ana Milagro-Beamonte ${ }^{12}$, María Ordobás ${ }^{2}$, Eva Martínez-Ochoa ${ }^{13}$, Socorro Fernández-Arribas ${ }^{4}$, Nicola Lorusso ${ }^{14}$, Ana Martinez ${ }^{6}$, Ana García-Fulgueiras ${ }^{7}$, Bartolomé Sastre-Palou ${ }^{8}$, Isabel Losada-Castillo ${ }^{15}$, Silvia Martínez-Cuenca ${ }^{10}$, Mar Rodríguez-del Águila ${ }^{11}$, Miriam Latorre-Millán ${ }^{12}$, and Amparo Larrauri ${ }^{1}$

${ }^{1}$ Carlos III Health Institute

${ }^{2}$ Dirección General de Salud Pública

${ }^{3}$ Dirección General de Salud Pública, Consumo y Cuidados

${ }^{4}$ Junta de Castilla y León Dirección General de Salud Pública

${ }^{5}$ Junta de Andalucia

${ }^{6}$ Agencia de Salud Pública de Cataluña

${ }^{7}$ Región de Murcia Consejería de Salud

${ }^{8}$ Hospital Universitari Son Espases

${ }^{9}$ Complejo Hospitalario Universitario de Santiago de Compostela

${ }^{10}$ Gobierno de Aragon

${ }^{11}$ Hospital Universitario Virgen de las Nieves

${ }^{12}$ Hospital Universitario Miguel Servet

${ }^{13}$ Dirección General de Salud Pública, Consumo y Cuidados, Servicio de Epidemiología y Prevención Sanitaria

${ }^{14}$ Junta de Andalucía

${ }^{15}$ Xunta de Galicia Conselleria de Sanidade

February 28, 2022

\begin{abstract}
Background: With the emergence of SARS-CoV-2, influenza surveillance systems in Spain were transformed into a new syndromic sentinel surveillance system. The Acute Respiratory Infection Surveillance System (SiVIRA in Spanish) is based on a sentinel network for Acute Respiratory Infection (ARI) surveillance in Primary care, and a network of sentinel hospitals for Severe ARI (SARI) surveillance in hospitals. Methods: Using a test-negative design and data from SARI admissions notified to SiVIRA between January 1 and October 3, 2021, we estimated COVID-19 VE against hospitalization, by age group, vaccine type, time since vaccination and SARS-CoV-2 variant. Results: VE was 89\% (95\% CI: 83-93) against COVID-19 hospitalization overall in persons aged 20 years and older. VE was higher for mRNA vaccines, and lower for those aged 80 years and older, with a decrease in protection beyond 3 months of completing vaccination, and a further decrease after 5 months. We found no
\end{abstract}


differences between periods with circulation of Alpha or Delta SARS-CoV-2 variants, although variant-specific VE was slightly higher against Alpha. Conclusions: The SiVIRA surveillance system, with a network of sentinel hospitals in Spain was able to describe clinical and epidemiological characteristics of SARI hospitalizations, monitor the circulation of SARS-CoV-2 and other respiratory viruses, and provide data to measure the effectiveness of COVID-19 vaccination in the population under surveillance. Our results add to evidence of high VE of mRNA vaccines against severe COVID-19 and waning protection with time since vaccination.

\section{Hosted file}

Title_page_authors_20220217_iorv_rev.docx available at https://authorea.com/users/462721/ articles/558082-covid-19-vaccine-effectiveness-against-hospitalization-due-to-sars-cov2-a-test-negative-design-study-based-on-sari-sentinel-surveillance-in-spain

\section{Hosted file}

Manuscript_sari_ve_20220217_iorv.docx available at https://authorea.com/users/462721/ articles/558082-covid-19-vaccine-effectiveness-against-hospitalization-due-to-sarscov-2-a-test-negative-design-study-based-on-sari-sentinel-surveillance-in-spain

\section{Hosted file}

Tables_and_figures_20220203.docx available at https://authorea.com/users/462721/articles/ 558082-covid-19-vaccine-effectiveness-against-hospitalization-due-to-sars-cov-2-a-testnegative-design-study-based-on-sari-sentinel-surveillance-in-spain 